\title{
BMJ A national survey of the infrastructure open and IT policies required to deliver computerised cognitive behavioural therapy in the English NHS
}

\author{
Holly Andrewes, ${ }^{1}$ David Kenicer, ${ }^{2}$ Carrie-Anne McClay, ${ }^{1}$ Christopher Williams ${ }^{1}$
}

To cite: Andrewes $\mathrm{H}$, Kenicer D, McClay C-A, et al. A national survey of the infrastructure and IT policies required to deliver computerised cognitive behavioural therapy in the English NHS. BMJ Open 2013:3:e02277.

doi:10.1136/bmjopen-2012002277

- Prepublication history and additional material for this paper are available online. To view these files please visit the journal online (http://dx.doi.org/10.1136/ bmjopen-2012-002277).

Received 28 October 2012 Revised 22 December 2012 Accepted 10 January 2013

This final article is available for use under the terms of the Creative Commons Attribution Non-Commercial 2.0 Licence; see http://bmjopen.bmj.com

For numbered affiliations see end of article.

Correspondence to Professor Chris Williams chris.williams@glasgow.ac.uk

\section{ABSTRACT}

Objective: This study aimed to identify if patients have adequate access to Computerised Cognitive Behavioural Therapy (cCBT) programmes in all mental health trusts across England.

Design: The primary researcher contacted a targeted sample of information technology (IT) leads in each mental health trust in England to complete the survey. Setting: Telephone, email and postal mail were used to contact an IT lead or nominated expert from each mental health trust.

Participants: 48 of the 56 IT experts from each mental health trust in England responded. The experts who were chosen had sufficient knowledge of the infrastructure, technology, policies and regulations to answer all survey questions.

Results: $77 \%$ of trusts provided computers for direct patient use, with computers in all except one trust meeting the specifications to access cCBT. However, $24 \%$ of trusts acknowledged that the number of computers provided was insufficient to provide a trust-wide service. $71 \%$ stated that the bandwidth available was adequate to provide access to CCBT sites, yet for many trusts, internet speed was identified as unpredictable and variable between locations. IT policies in only $56 \%$ of the trusts allowed National Health Service (NHS) staff to directly support patients as they complete CCBT courses via emails to the patients' personal email account. Only $37 \%$ allowed support via internet video calls, and only $9 \%$ allowed support via instant messaging services.

Conclusions: Patient access to cCBT in English NHS mental health trusts is limited by the inadequate number of computers provided to patients, unpredictable bandwidth speed and inconsistent IT policies, which restrict patients from receiving the support needed to maximise the success of this therapy. English NHS mental health trusts need to alter IT policy and improve resources to reduce the waiting time for psychological resources required for patients seeking this evidence-based therapy.

\section{INTRODUCTION}

There is an increasing need to improve access to psychological therapies for patients with mental health problems in the UK. ${ }^{1}$

\section{ARTICLE SUMMARY}

Article focus

- This paper investigates the extent to which all mental health trusts in England provide adequate infrastructure, software, internet speed and support for patients to access and successfully undertake computerised cognitive behavioural therapy (cCBT).

Key messages

- CCBT is recommended by NICE for treatment of depression and anxiety.

- The Department of Health in England has also shown a firm commitment to this therapy through its recommendation as a first step in the Increasing Access to Psychological Services (IAPT) programme.

- Despite this commitment, the results of this study show that the majority of mental health trusts in England do not provide the infrastructure, internet speed and support required to provide unrestricted access to CCBT in NHS trusts.

Strengths and limitations of this study

- Nationwide study of all mental health trusts across England.

- Investigates an issue, which is currently part of NICE-recommended treatment for depression and therefore relevant to the health sector. This paper is an important step for instigating decisions and actions within the trusts.

- Comparisons made between access to cCBT in mental health trusts across England and Scotland.

- Imperfect knowledge of participants to accurately comment on all IT infrastructure and policies across all aspects of their trust.

Cognitive behavioural therapy (CBT), delivered to individuals in face-to-face sessions, usually lasting $12-16$ weeks, is known to be effective in the treatment of various conditions such as depression, anxiety and bulimia nervosa. ${ }^{2-4}$ However, this type of therapy is labour intensive and is delivered 
by highly qualified therapists. As an alternative, the National Institute of Clinical Excellence (NICE) recommends guided self-help and computerised cognitive behavioural therapy (cCBT) for the treatment of eating disorders (2004), ${ }^{5}$ anxiety disorders (2006), ${ }^{6}$ mild to moderately severe depression $(2009)^{7}$ and 'common mental health problems' $(2011)^{8}$ as a first step in a stepped care model for the treatment of various mental health problems.

The primary aim of the stepped care model of treatment is to reduce waiting lists for specialist therapy and improve the capacity and efficiency of services. ${ }^{1}$ The concept of stepped care outlines that patients should receive the least restrictive treatment available and that progress should be continually monitored and treatment adapted when necessary. The lowest intensity treatment in the stepped care model includes guided/supported cCBT as well as the use of structured CBT self-help books (bibliotherapy). ${ }^{9}$ $\mathrm{NICE}^{7}$ also recommends that cCBT should be guided or supported by a practitioner as the addition of support/ guidance significantly improves patient outcomes. This support can be offered in different ways including face to face, telephone and email. ${ }^{10}$

There are many benefits to cCBT, including the potential to reduce the waiting times for therapy. ${ }^{11}$ It may also offer convenience by allowing the patient to login at home, save travel time and increase confidentiality for potentially stigmatising illnesses. ${ }^{12}$ A number of systematic and meta-review papers assessing the efficacy of cCBT for the treatment of mild to moderate depres$\operatorname{sion}^{13}{ }^{14}$ and anxiety ${ }^{15}$ have shown that cCBT is as effective as therapist-led cognitive behavioural therapy, despite requiring less therapist time. These findings have led to the recommendation that $\mathrm{CCBT}$ be integrated into routine practice for the treatment of depression ${ }^{13}$ and anxiety disorders. ${ }^{15}$ The approach has also been added to the range of delivery offered through the Increasing Access to Psychological Treatment (IAPT) government programme across England. ${ }^{16}$

Health is devolved and organised into mental health boards rather than mental health trusts, as it is in England. Here also, a firm national commitment to the use of new health technologies has been made by the Health Department in Scotland. ${ }^{17}$ Despite this, a recent national survey of the provision of cCBT within Scottish National Health Service (NHS) mental health boards highlighted that patient accessibility to cCBT within the NHS is restricted by local Information Technology (IT) policies, software and equipment availability. ${ }^{18}$ That survey found that $64 \%$ of health boards do not provide dedicated computers for patient use, and $36 \%$ do not permit members of staff to offer email contact or support to patients. This means that email support sessions (a valuable component of the guided self-help approach) cannot be delivered. The findings of the survey of Scottish health boards overall indicated that the majority of patients would be unable to utilise this form of therapy if attempting to access via computers within NHS settings.
Allowing patients to access cCBT sites using NHS computers is important to ensure that patients can still benefit from this treatment even if they cannot or do not wish to access these sites privately at home because of lack of equipment or poor broadband speeds. The 2011 census showed that 23\% of households in England do not have internet access. ${ }^{19}$ In London, the region with the highest population density, $83 \%$ have internet connection; however, in the northeast of England, an area with the lowest population density, home internet connection is as low as $59 \% .^{20}$ Although $83 \%$ of households in London have internet access at home, many of the houses in these areas are small with limited privacy for members of a household wanting to privately access these sites. ${ }^{21}$ On the other hand, less densely populated areas of England, such as the North East, are both less likely to have access to internet in the home and have slower internet connections which may not be adequate to fully utilise cCBT sites. Slower internet speeds in rural areas are attributable to a lower number of houses having access to cable broadband. ${ }^{22}$

With the rise of the IAPT $^{16}$ programme across England, the present study aims to ascertain the extent to which IT infrastructure and local IT policy across English mental health trusts support the delivery of cCBT for mental health problems. This study utilises the same survey methodology as the previous Scottish study $^{18}$ and also allows a comparison of progress to achieve wider delivery in both countries.

As in the previous survey, the current study focused on three key areas of interest: access to computers in trusts, specifications of computers and, finally, IT policies concerning contact with patients. The results of this survey were intended to provide valuable information regarding the extent to which English mental health trusts can effectively deliver and support the guided self-help approach using computer-based packages in order to increase access to psychological therapies, increase service efficiency and reduce patient waiting times.

\section{METHODS \\ Design}

IT managers from all 58 mental health trusts in England were identified and approached between 15 January 2012 and 19 March 2012 to complete a short telephone survey investigating the technology, infrastructure and IT regulations. Participants who were unable to complete the survey over the phone were sent the survey to complete via email. The remaining mental health trusts, who could either not be contacted or could not complete the survey by telephone or email, were sent the survey by postal mail. A standardised pro forma was used to structure the interview, which took approximately $5-10 \mathrm{~min}$.

\section{Participants}

The sample comprised IT managers or directors, or nominated engineers, and technical team leaders from 
48 of the 58 mental health trusts on the mainland of England. In the cases where the IT representative could not answer an IT policy question, a representative from the mental health trust's information governance and policy department was contacted. As the sample included only NHS staff members and no patients were involved in the survey, NHS research ethics approval was not needed for the study.

\section{Setting}

The mainland of England has been divided into 58 mental health trusts. Each trust covers a region of England and is responsible for providing health and social care services and facilities within that area. ${ }^{23}$ Mental health trusts vary significantly in the size of area and number of facilities, which the trust is responsible for. Weightings of importance were not given to questionnaire responses from larger trusts because the authors considered access to cCBT in smaller NHS trusts in rural or lower socioeconomic areas to be as important owing to lower numbers of home internet access in this area.

\section{Procedure}

Each mental health trust was initially contacted by telephone before being contacted by email and/or postal mail between January 2012 and March 2012. Participants completed an 11-point survey covering key areas of interest including patient access to computers within the health board, if the specifications of computers met those required to access cCBT packages and if sufficient staff support could be provided to these patients. An open-ended question was included at the end of the survey to allow participants to state any other barriers preventing patient access to cCBT in their trust that had not already been mentioned.

\section{RESULTS}

The survey question responses have been analysed and summarised under five main categories: (1) access: referring to whether patients had access to dedicated computers to use cCBT packages on NHS premises; (2) specifications: identified the technological capabilities of NHS trust computers and determined whether they allowed the use of Flash, Java and PDF (Portable Document Format) reader, which are often required in cCBT packages; (3) contact: the extent to which staff members are permitted to support patients' use of selfhelp resources through various support mediums; (4) other barriers preventing patient access to cCBT packages within the NHS trusts and (5) comparison between the England and Scotland survey findings. See table 1 for a full summary of responses from English mental health trusts.

\section{Access}

The results of the survey show that $37(77 \%)$ of the 48 responding mental health trusts in England provide routine computer and internet access directly to patients. However, 9 (24\%) of these trusts acknowledged that the number of computers they provided for patient use was inadequate to ensure a trust-wide service for patients to access cCBT sites. Many trusts noted that the number of patient computers varied between locations with some hospitals not currently providing any patientdedicated computers. Others acknowledged that the overall number of computers provided in each location was too low with four of these trusts providing as few as two computers in total across the entire trust. Furthermore, some trusts only provided computer access to inpatients. At the locations where computers were provided for patients, most were either closely monitored or took the form of an internet kiosk. The 11 (22.9\%) remaining mental health trusts that replied to the survey did not

\begin{tabular}{|c|c|c|c|}
\hline Access & Yes (\%) & No (\%) & Unsure (\%) \\
\hline Patient access to computers in trust? & $37(77)$ & $11(23)$ & $0(0)$ \\
\hline Allow patient access to cCBT sites? & $41(85)$ & $2(4)$ & $5(11)$ \\
\hline Patient access to internet with adequate speed? & $34(71)$ & $11(25)$ & $3(4)$ \\
\hline \multicolumn{4}{|l|}{ Specifications of NHS computers* } \\
\hline Computer specifications meet requirements? & $36(97)$ & $1(3)$ & $0(0)$ \\
\hline Does the computer have Java Script? & $36(97)$ & $1(3)$ & $0(0)$ \\
\hline Flash video? & $37(100)$ & $0(0)$ & $0(0)$ \\
\hline Is video streaming allowed? & $22(59)$ & $8(22)$ & $7 \dagger(19)$ \\
\hline Is audio streaming allowed? & $25(68)$ & $5(13)$ & $7 \dagger(19)$ \\
\hline \multicolumn{4}{|l|}{ Support for patients } \\
\hline Can NHS staff email to patients' private/personal email accounts? & $26(54)$ & $22(46)$ & $0(0)$ \\
\hline Can patients have an NHS-approved email account? & $1(5)$ & $21(95)$ & $0(0)$ \\
\hline Do the computers have video support/instant messaging? & $4(8)$ & $44(92)$ & $0(0)$ \\
\hline Would the staff be allowed to provide support via video conferencing? & $17(35)$ & $31(65)$ & $0(0)$ \\
\hline
\end{tabular}


provide the use of any computers with internet access. Patients in these trusts are currently unable to access cCBT sites within NHS buildings and must therefore rely on alternative resources (such as personal or library computers, if available).

Participants were asked whether broadband internet speed was adequate for multiple patients to access and use the cCBT sites simultaneously within the NHS trust. This question was asked irrespective of whether their mental health trust currently provided computers. Video streaming on the cCBT sites was identified as the greatest strain on the bandwidth. Therefore, IT representatives were asked whether five patients, for example, on a cluster of computers could stream audio and video simultaneously with a delay of less than $20 \mathrm{~s}$. Thirty-four of all 48 trusts $(71 \%)$ stated that their bandwidth speed in the majority of locations within their trust was fast enough to allow this. However, most participants acknowledged that the speed of their internet varied between locations, with most regional locations experiencing broadband speeds that were too slow to fulfil this requirement.

Participants were then asked whether their trust would, in theory, allow patients to access cCBT sites in their NHS buildings. Overall, $41(85 \%)$ trusts stated that they would allow access to cCBT sites from their computers. Only two participants stated that their trust would not allow this, and five were unsure, stating that such decisions were within the clinicians remit, rather than the IT department.

\section{Specification of NHS computers}

All mental health trusts in England, except one, with patient computer access stated that their computers met the specifications required to allow access to cCBT websites $(\mathrm{n}=36 ; 97 \%)$. Java and Flash video (which commonly deliver audio and video) operated on computers in all trusts except one, and all trusts allowed PDFs to be opened. Twenty-two trusts $(63 \%)$ with computers available to patients allowed video streaming and 25 allowed audio streaming $(71 \%)$. However, the amount of video and audio that patients could stream was restricted in most trusts due to the resulting strain on internet speed. Seven additional trusts (19\%) allowed video and audio streaming by request.

\section{Contact/support with patients}

The third area investigated whether practitioners and healthcare workers could provide the active support and guidance as recommended by NICE (2009) and Scottish Intercollegiate Guidelines Network (SIGN) (2010) for users of cCBT. Over half $(n=26 ; 54 \%)$ of the mental health trusts allowed practitioners to email patients' personal email accounts in order to offer support. Thirteen $(50 \%)$ of the trusts that allowed this protected the patients' privacy through the use of encrypted emails. Eight $(31 \%)$ of these trusts required written consent from the patient. Two primary reasons were noted for why the remaining $22(46 \%)$ trusts would not allow this form of support. First, personal email accounts were not considered as secure and were therefore vulnerable to data leakage. Second, participants mentioned the risk of mis-addressing emails. To improve the security of personal email accounts, it was suggested that patients be provided with an NHS email account. However, only one trust considered this to be a feasible solution.

As an alternative method of support, trusts were asked if they utilised video face-to-face conferencing such as Skype or live chat messenger services such as MSN. As few as $4(8 \%)$ of these trusts provided these applications for patient use. However, only $17(35 \%)$ of all trusts stated that their IT policies would allow video face-to-face support to be implemented and used for support if it were required. Most trusts that would not allow video support reasoned that this would put too much strain on the bandwidth, which in many locations was already too slow. Live (synchronous) chat (such as MSN messenger), on the other hand, was not allowed by any additional trusts as there is no method of verifying the identity of the person receiving support; nor could it provide a record of conversations for future reference.

\section{Further barriers to the application of CCBT}

The IT representatives for the trusts were asked about any other barrier to cCBT that had not already been mentioned. Most trusts reiterated that the number of computers and the unpredictable internet speed across the trusts were the major barriers to patient access to cCBT in their trust. However, $35 \%$ of all IT representatives were also concerned about the cost of supervision, infrastructure and IT support that would be required if more computers with internet access were made available to patients. Many trusts were also concerned about the number of staff required to support patients as they accessed cCBT $(\mathrm{n}=11,23 \%)$.

\section{Comparison of English NHS trust results with Scottish NHS trust results}

The $\chi^{2}$ goodness-of-fit tests indicate that English NHS trusts are more than twice as likely to provide access to patient computers and 14\% more likely to allow access to cCBT websites (table 2). However, there were no significant differences between countries in infrastructure quality (computer specification) or in the ability of staff to offer support between the current audit and the previous survey in Scotland (table 2).

\section{DISCUSSION}

cCBT is an important therapeutic resource for patients with anxiety or depression. 8 Access to this form of therapy may be particularly useful for patients requiring low-intensity therapy and for those who find it difficult to seek help from a therapist due to the waiting time or fear stigmatisation. ${ }^{11}{ }^{12}$ The effectiveness of cCBT for treating anxiety and depression has been acknowledged 
Table 2 Comparison between responses from Scottish and English mental health trusts

\begin{tabular}{|c|c|c|c|c|}
\hline Access & $\begin{array}{l}\text { England } \\
\text { Yes (\%) }\end{array}$ & $\begin{array}{l}\text { Scotland } \\
\text { Yes (\%) }\end{array}$ & $\chi^{2}$ & $\begin{array}{l}\text { Compare } \\
\text { Significance }(p)\end{array}$ \\
\hline Patient access to computers in trust? & $37(77)$ & $5(36)$ & 35.16 & $<0.001$ \\
\hline Allow patient access to cCBT sites? & $41(85)$ & $10(71)$ & 12.78 & $<0.001$ \\
\hline \multicolumn{5}{|l|}{ Specifications of NHS computers* } \\
\hline Do the computer specifications meet the requirements? & $36(97)$ & $14(100)$ & 1.10 & 0.29 \\
\hline Does the computer have Java Script? & $36(97)$ & $12(86)$ & 1.10 & 0.30 \\
\hline Flash video and PDF? & $37(100)$ & $12(86)$ & 1.10 & 0.30 \\
\hline \multicolumn{5}{|l|}{ Support for patients } \\
\hline Can NHS staff email to patients' private/personal email accounts? & $26(54)$ & $9(64)$ & 2.02 & 0.52 \\
\hline Can patients have NHS-approved email account? & $1(5)$ & $1(0.7)$ & 0.25 & 0.62 \\
\hline Do computers have video support/instant messaging? & $4(8)$ & $1(0.7)$ & 0.13 & 0.72 \\
\hline
\end{tabular}

*Only asked to trusts that currently provided patients with access to computers.

cCbt,Computerised Cognitive Behavioural Therapy; NHS, National Health Service; PDF,Portable Document Format.

in a number of randomised control trials. ${ }^{24} 25$ It has since been recommended as a standard first-step treatment for depression and anxiety by metareviews as well as by NICE $(2004,2006,2009,2011) .^{5-8}$ The Department of Health in England has also recommended cCBT as part of the IAPT initiative as a lowintensity alternative to reduce the costs, resources and waiting time for patients seeking therapy. ${ }^{16}$ Without access to this form of therapy within the NHS buildings, many patients without internet access, ${ }^{19}$ inadequate internet speed ${ }^{21}$ or those finding it difficult to maintain privacy in the home ${ }^{22}$ may feel unable to engage and access this treatment option.

The results of the current survey have revealed that computer access with an acceptable internet speed is provided at least partially for patients in over $70 \%$ of English mental health trusts. Furthermore, almost all trusts will allow access to cCBT sites if this is required. It is also encouraging that all patient computers provided in English trusts, except one, meet the specifications required for patients to gain access to cCBT sites. Despite these impressive results, approximately a third of all trusts that provide computers acknowledge that the number of computers in their trust is inadequate to provide a trust-wide service. Many trusts also state that some of their smaller, rural locations do not provide any patient computers. The vast majority of respondents accept that internet speed is highly variable across locations within their trust region, with some sites, particularly outside towns and cities, receiving unpredictable internet speed, which is likely to be too slow for patients to undertake cCBT. As a consequence of the strain on internet speed, video and audio streaming are also restricted in these trusts. This shows that although the majority of mental health trusts provide computer and internet access, patients cannot be guaranteed access to these services at their closest NHS facility at the present time.

National English treatment guidelines recommend that cCBT for depression is most successful when brief supportive monitoring is provided by trained staff. $^{7}$ However, according to the survey, IT policy restricts the ways in which NHS staff can provide this support. Almost half of all English trusts prohibited staff from emailing patients' private email accounts. This is compounded by the fact that only one trust could provide patients with an NHS email account to improve security of email transmission. This is a matter of concern given that evidence points to the importance of therapeutic support, with a review showing a strong correlation between therapist input or support and patient outcome. ${ }^{26}$ Furthermore, almost every English trust fails to currently provide face-to-face video conferencing or live/synchronous chat-style support, and only a third of all trusts state that they could allow and install video conferencing if this was required.

The flexibility and convenience of being provided with these support methods may make cCBT especially attractive when the time and cost of transport required to attend face-to-face appointments are high, or when patients have additional problems such as anxiety, physical disability or commitments as a carer or childminder. The full range of flexible support for cCBT may include telephone, email, instant messenger or live video support. The aim in each case is to support and motivate the user to apply the cCBT content to their own lives.

Overall, $77 \%$ of trusts provided access to computers with internet access at specific sites. However, only 4 of the 48 respondents $(8 \%)$ of mental health trusts in England provide the infrastructure, internet speed, computer specifications and staff support required for trustwide access to cCBT. Furthermore, even in these cases where the basic requirements for cCBT access were fulfilled, these trusts and others highlighted further barriers that could prevent patients from accessing cCBT. The first included an acknowledgement that the computers currently provided were not sufficiently private for patients to discreetly complete the therapy. The second was a concern for the costs of infrastructure and resources required to support patients to access cCBT as 
a trust-wide service. It is disappointing that the latter is believed to be a major barrier to cCBT access given that NICE $(2006)^{6}$ previously estimated that if cCBT were implemented correctly, this therapy would ultimately save the NHS £126 million/year.

Despite the IAPT government initiative that encourages access to $\mathrm{cCBT}^{16}$ and recommendations from NICE promoting its use for anxiety, ${ }^{6}$ depression ${ }^{7}$ and common mental health problems, ${ }^{8}$ most English mental health trusts are yet to provide facilities and support that allow patients trust-wide access to cCBT. This study highlights that the adoption of cCBT is variable across locations owing to a lack of infrastructure and internet speed, leaving many patients without access.

The comparison between NHS mental health boards in Scotland and English NHS mental health trusts found no differences in IT infrastructure or in the (low) ability of staff to provide support for patients. However, IT policies were more likely to be restrictive in Scotland with English trusts being more than twice as likely to provide patients with computer and internet access, and significantly more likely to allow patients access to cCBT sites on their computers. ${ }^{18}$

No other studies to date have audited the accessibility of cCBT within NHS trusts. A limitation of this study includes the knowledge of the IT representatives completing the survey. Owing to the size and complexity of each mental health trust, it is possible that some IT representatives may not have been fully informed of all IT systems, policies and procedures in all hospital locations across a trust. However, although this is possible, it is unlikely to be a major limitation as all IT representatives were chosen for their position and expertise and ability to adequately answer all questions with relative ease.

The current investigation is an important step forward in highlighting the policies, procedures, infrastructure and accessibility issues which may act to prevent patients from accessing cCBT in the English NHS mental health trusts. To supplement the local delivery of cCBT, it may be that an alternative delivery can be supported by centrally funded NHS organisations, which have a national remit such as NHS Direct (England) and NHS24 (Scotland). Both provide telephone access, self-referral, triage and handling of medical care to sift patients between primary and emergency care. Both are currently experimenting with providing support for lowintensity interventions with the Health Lines study ${ }^{27}$ and NHS Living Life (Scotland). ${ }^{28}$ It may be possible, therefore, for the alternative route of national access to be provided through a robust infrastructure and open access policies that encourage guided support within such organisations.

Repeated future investigation is required at a later date to identify if infrastructure and internet access can be improved in smaller and more rural locations within each trust. An investigation into why IT policies differ between trusts, as well as the impact this has on the adoption of cCBT and implementation of national guidance, would also be beneficial to increase standardisation of policies and improve patient support.

Author affiliations

${ }^{1}$ Institute of Health and Wellbeing, University of Glasgow, Gartnavel Royal Hospital UK, Glasgow, UK

${ }^{2}$ NHS Greater Glasgow and Clyde, Gartnavel Royal Hospital, Glasgow, UK

Acknowledgements We wish to thank those in the various IT departments within the NHS Trusts in England who shared their expertise and experience to help inform the study.

Contributors HA carried out data collection and results analysis and completed the writing of the Method, Results and Discussion sections. DK performed data collection and was the editor of the paper. CAM performed liaison for data-collection progress, and completed the writing of the Introduction section and editing comments on the whole paper. CW carried out the design, liaison for data collection and was the editor of the paper. All authors have approved the final published paper.

Funding This research received no specific grant from any funding agency in the public, commercial or not-for-profit sectors.

Competing interests CW is an author of a variety of written and CCBT resources, which are licensed through Five Areas Ltd, a company that delivers free and licensed online life skills resources based on a CBT model in a variety of settings including the NHS in Scotland and England. CW was involved in the design and writing up of the study, but he was not involved in the data collection or analysis. CAM is completing a PhD with the University of Glasgow and was employed by both the University of Glasgow and Five Areas Ltd during the course of this research. CAM was neither involved in the design of the study nor the data collection and analysis.

Ethics approval The participants included NHS staff members. Therefore, as no patients were involved in the survey, NHS research ethics approval was not needed for the study.

Provenance and peer review Not commissioned; externally peer reviewed.

Data sharing statement There are no additional data available. Access to the original survey responses and Excel datasheets of responses can be provided on request.

\section{REFERENCES}

1. Bower P, Gilbody S. Stepped care in psychological therapies: access, effectiveness and efficiency: narrative literature review. BJPsych 2005;186:11-17.

2. Butler AC, Chapman JE, Forman EM, et al. The empirical status of cognitive-behavioral therapy: a review of meta-analyses. Clin Psychol Rev 2006;26:17-31.

3. James AACJ, Soler A, Weatherall . Cognitive behavioural therapy for anxiety disorders in children and adolescents. Cochrane Database Syst Rev 2009. http://onlinelibrary.wiley.com/store/10. 1002/14651858.CD004690.pub2/asset/CD004690.pdf? $\mathrm{v}=1 \& \mathrm{t}=\mathrm{h} 8 \mathrm{lsypop} \& \mathrm{~s}=80 \mathrm{fb} 05 \mathrm{dcfeba} 1 \mathrm{bbfbe} 6503902 \mathrm{f} 54 \mathrm{bd} 886 \mathrm{~d} 48 \mathrm{c} 198$ (accessed 22 Oct 2012).

4. Hay PP, Bacaltchuk J, Stefano S, et al. Psychological treatments for bulimia nervosa and binging. Cochrane Database Syst Rev 2009;7: CD000562.

5. NICE-National Institute for Clinical Excellence. Eating disorders: core interventions in the treatment and management of anorexia nervosa, bulimia nervosa, and related eating disorders. London. 2004. http://www.nice.org.uk/nicemedia/pdf/cg009publicinfoenglish. pdf (accessed 22 Oct 2012).

6. NICE-National Institute for Clinical Excellence. Computerised cognitive behaviour therapy for depression and anxiety: guidance. TA97. London. 2006. http://www.nice.org.uk/nicemedia/live/11568/ 33187/33187.pdf (accessed 22 Oct 2012).

7. NICE-National Institute for Clinical Excellence. Depression: management of depression in primary and secondary care. CG90. London, 2009. http://www.nice.org.uk/nicemedia/live/12329/45888/ 45888.pdf (accessed 22 Oct 2012). 
8. NICE-National Institute for Clinical Excellence. Common mental health disorders, 2011. http://www.nice.org.uk/nicemedia/live/13476/ 54520/54520.pdf (accessed 20 Nov 2012).

9. Ridgway N, Williams C. Cognitive behavioural therapy self-help for depression: an overview. J Ment Health 2011;20:593-603.

10. Gellatly J, Bower P, Hennessy S, et al. What makes self-help interventions effective in the management of depressive symptoms? Meta-analysis and meta-regression. Psychol Med 2007;37:1217-28.

11. Carlbring P, Andersson G. Internet and psychological treatment. How well can they be combined? Comput Hum Behav 2006;22:545-53.

12. Marks IM, Cavanagh K, Gega L. Maudsley monographs no. 45. Hands-on help: computer-aided psychotherapy. Hove, UK: Psychology Press, 2007

13. Foroushani S, Schneider $\mathrm{P}$, Assareh N. Meta-review of the effectiveness of computerised CBT in treating depression. BMC Psychiatry 2011;11:131.

14. Kaltenthaler E, Parry G, Beverley C, et al. Computerised cognitive-behavioural therapy for depression: systematic review. $\mathrm{Br} \mathrm{J}$ Psychiatry 2008;193:181-4.

15. Cuijpers P, Marks MI, Annemieke van S, et al. Computer-aided psychotherapy for anxiety disorders: a meta-analytic review. Cognit Behav Ther 2009;38:66-82.

16. Department of Health. IAPT Implementation Plan: National Guidelines for Regional Delivery. 2008. http://www.iapt.nhs.uk (accessed Jun 22 2012).

17. Scottish Government: NHS Scotland Chief Executive's Annual Report 2010/11. http://www.scotland.gov.uk/Publications/2011/11/ 10140644/4 (accessed 22 Oct 2012).

18. Kenicer D, McClay C, Williams C. A national survey of health service infrastructure and policy impacts on access to computerised CBT in Scotland. BMC Med Inform Decis Mak 2012;12:102.
19. Office for National Statistics. Statistical Bulletin: Internet accessHouseholds and Individuals. 2011. http://www.ons.gov.uk/ons/rel/ rdit2/internet-access--households-and-individuals/2011/index.html (accessed 26 Jun 2012).

20. Office for National Statistics. Statistical Bulletin: Internet accessHouseholds and Individuals. 2010. http://www.ons.gov.uk/ons/rel/ rdit2/internet-access--households-and-individuals/2010/index.html (accessed 26 Jun 2012).

21. Office for National Statistics. 2011 census. Population household estimates for England and Wales. http://www.ons.gov.uk/ons/ dcp171778_270487.pdf (accessed 20 Nov 2012).

22. Ofcom infrastructure report. 2012. http://d2a9983j4okwzn.cloudfront. net/downloads/ofcom-uk-broadband-speed-report-2012.pdf (accessed 20 Nov 2012).

23. About the NHS-mental health trusts.http://www.nhs.uk/ NHSEngland/thenhs/about/Pages/authoritiesandtrusts. aspx\#mentalhealth (accessed 23 Nov 2012).

24. Høifødt RS, Strøm C, Kolstrup N, et al. Effectiveness of cognitive behavioural therapy in primary health care: a review. Fam Pract 2011;28:489-504.

25. Proudfoot J, Ryden C, Everitt , et al. Clinical efficacy of computerised cognitive-behavioural therapy for anxiety and depression in primary care: randomised controlled trial. BJP 2004;185:13-1.

26. Palmqvist $B$, Carlbring $P$, Andersson $G$. Internet-delivered treatments with or without therapist input: does the therapist factor have implications for efficacy and cost? Expert Rev Pharmacoecon Outcomes Res 2007;3:291-7.

27. HealthLines-ISRCTN Register. http://www.controlled-trials.com/ ISRCTN27508731/ (accessed 28 Nov 2012).

28. NHS 24: Health Information and Self-Care Advice for Scotland. http:// www.nhs24.com/UsefulResources/LivingLife. (accessed 27 Nov 2012). 